quent following of its motion (see Fig. 1) by the electron cloud, it might well be asked whether this exotic atom is in fact an atom at all, as it looks more like a slowly rotating molecule in its lowest vibrational state. The etymologically unsound but evocative name "atomcule" perhaps describes this rather strange new object best.

\section{Spectroscopy}

The microsecond lifetimes already observed are long enough to carry out spectroscopy on these objects and the first such experiment is planned for the next few months. The LEAR parasitic beam of several thousand $\bar{p}$ per second produces about 400 atomcules per second. Spectroscopy on the basis of individual atoms can be done if we can actually "find" single atomcules among the $10^{23}$ normal helium atoms. This is not such a tall order as one might think. Calculations based on the Condo-Russell model suggest that non-metastable states (i.e., with lifetimes of order ns or less) exist within $2 \mathrm{eV}$ and one unit of angular momentum of the metastable ones. If the helium target is irradiated by a laser tuned to a stable - metastable transition every time a metastable state is formed, the $\bar{p}$ can be induced to annihilate instantly via Auger ejection of the second electron and Stark induced transitions in field of neighbouring ordinary helium atoms. Observation of this forced annihilation at the predicted frequency would be a very clear indication that the atomic model is valid.

If it is valid, what next? Are there longerlived components present in the annihilation time spectrum which have so far not been observed? Would it be possible to excite these peculiar atoms from identified metastable states to even longer-lived ones, and what can we learn from their fine and hyperfine structures? These and many other interesting prospects await investigation in the near future.

[1] Eades J., Europhysics News 21 (1990) 27 [2] Atomic Data and Nuclear Data Tables 27, iii (Academic Press) 1982.

[3] Iwasaki M. et al., Phys. Rev. Lett. 67 (1991) 1246.

14] Yamazaki T. et al., Nature 361, No. 6409 (1993) 238.

[5] Condo G.T., Phys. Lett. 9 (1964) 65. [6] Russell J.E., Phys. Rev. Lett. 23 (1969) 63 Phys. Rev. 188 (1969) 187; Phys. Rev. A 1 (1970) 721, 735, 742; J. Math. Phys. 12 (1971) 1906; Phys. Rev. A 6 (1972) 2488.

[7] Ahlrichs R. et al., Z. Phys. A 306 (1982) 297.

[8] Shimamura I., Phys. Rev. A 46 (1992) 3776; Yamazaki T. and Ohtsuki K., Phys. Rev. A 45 (1992) 7782; Greenland P.T. and Thürwächter R., Hyperfine Interactions 76 (1993) 355.

\section{History of Physics in Europe in the 19th and 20th Centuries \\ Proceedings of the 1st EPS Conference Como, 2-3 September 1992 Edited by $F$. Bevilacqua \\ Orders:}

Società Italiana di Fisica

Via Castiglione, 101, I-40136 Bologna

Tel./Fax: +39 (51) $331554 / 581340$

Price: LIT 80000 - (EPS members: less $10 \%$ )

\title{
Life After the Soviet Union
}

\section{Christoph Schneider \\ IIASA, Laxenberg}

Scientific talent displayed by advances in research and development (R\&D) is an extraordinarily valuable national resource; one that requires significant investment, foresight and political attention. R\&D has become an essential ingredient for modern economic growth. Russia inherited such a resource $70 \%$ of the former Soviet Union's scientific capacity was located there.

In 1989, the Soviet R\&D community numbered almost 1.7 million scientists, engineers and technicians. Only the USA, with 2.0 million, had more. Reaching its peak in 1990 and declining thereafter, the Soviet figure in 1989 of 104 scientific workers in R\&D per 10000 people in the labour force was impressive. It was 1.54 times the Japanese, 1.57 times the American, 1.97 times the West German, and 2.93 the British levels. Of this R\&D personnel, as much as $76.8 \%$ were employed in the branch sector (industry), $13 \%$ by the Academy of Sciences, and only $10 \%$ in institutes of higher education. These shares were still representative of the situation in 1992, except for some minor adjustments. In 1991, over two-thirds of research personnel were in engineering, physics and mathematics, although the proportion is now decreasing in favour of neglected areas such as economics, biology, and medicine. In addition, the older generation was predominant. Indeed, almost $80 \%$ of the highest level scientists were over 50 years of age in the late-1980's (see figure).

Soviet scientists and engineers typically worked in huge, inflexible organizations: the 5111 R\&D institutions existing in 1989 had an average of 300 scientists (some had tens of thousands). Almost all scientific establishments and personnel were in Russia; Kiev, Kharkov and Riga were the only sizeable centers beyond its borders. For practical purposes, Soviet science was Russian science.

Soviet scientific capability was built at great expense. From the late-1950's to the late-1980's, Soviet spending on R\&D as a percentage of gross national product was consistently higher than in western countries, reaching nearly $5 \%$ in 1989 - more that twice the OECD average. Some $75 \%$ of the financing was in technical fields (dominated by mathematics and physics) and little was allocated to the medical or biological sciences, again quite contrary to the OECD picture (Table 1).

Under the former Soviet policy framework, the separation of R\&D fields under different hierarchies led ministries, academies, and state committees to having their own institutes with many doing complementary or even over-lapping work. All this required considerable staff, many of whom were duplicating a job in another organization. Institutes

Christoph Schneider is a research scholar at the International Institute for Applied Systems Analysis, A-2361 Laxenberg. While at IIASA, he received a Ph.D. from the Economics University, Vienna, for work on restructuring R. \& D. in Russia. He presently participates in a study of economic transition and integration in the former Soviet Union.

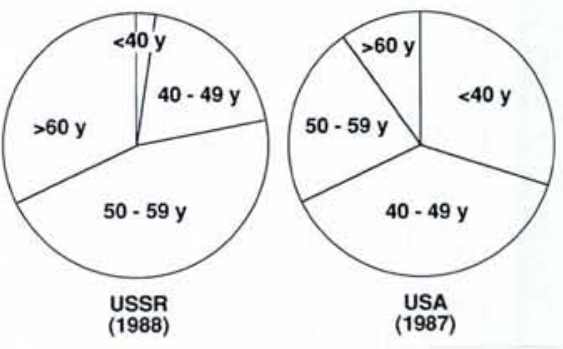

Age structure of scientific workers with the highest qualifications.

wanted to be self-reliant; information was not shared because each had to negotiate with the centre to obtain as large a financial allocation as possible. The idea was that large projects required large staffs and would draw large budget allocations.

\section{Some Changes}

The first year of reform caused the gross domestic product to decline by one-fifth; price increases led to hyperinflation, tax revenues plunged, state budget expenditure came under severe pressure, and enterprises embarked on an unprecedented struggle for survival. Russia's R\&D sector was one of the first to feel the crunch. Caught between the need for long-term investment and the desire for short-term gains, R\&D suffers more than other activities when decision-makers' time horizons shrink, which has increasingly been the case as the transition continues.

As a result of the disintegration of the structures and principles that formed and nurtured it, the R\&D establishment in Russia is itself precariously close to collapse during the transition to a market economy. In addition, the features characteristic of a healthy economy required to procure scientific and technological progress are insufficient in present-day Russia. However, R\&D itself has not yet changed much. This is because basic science was relatively inexpensive and received less funds than applied science and experimental activity. In addition, figures indicate that enterprises had little interest in fundamental research and a greater portion of them already began in the late 1980's to invest in industrial applied R\&D.

While $7.25 \%$ of the government budget was destined for R\&D in 1990, it dropped to only $3.4 \%$ in 1992 . This was mainly due to the drastic cuts in defense contracts, which had previously accounted for up to $70 \%$ of state budget allocations for R\&D: 1993 will see another drop in government financing for $R \& D$ in real terms. Also, the fixed subsidy from the state budget for the Academy of

(continued on p. 179) >

Table 1 - Distribution of government expenditures for research (1988, in percent). OECD figures are for 1987 in life sciences? physical sciences and engineering ${ }^{2}$, and social sciences and psychology?

\begin{tabular}{lrrc}
\hline Science & USSR & USA & OECD av. \\
\hline natural & 16.0 & 29.7 & \\
medical & 2.2 & 10.2 & $36.2^{1}$ \\
agricultural & 2.4 & 3.9 & \\
technical & 75.3 & 50.2 & $33.5^{2}$ \\
social/humanities & 4.1 & 6.0 & $6.8^{3}$ \\
\hline
\end{tabular}


Sciences has become vulnerable to change, delaying payments and causing numerous academic institutions to lose scientists to the budding non-state R\&D sector and other parts of the economy (not to mention those who ventured abroad). However, the government has promised special budget allocations for a large number of target-oriented science and technology programmes. Those involved in space transport, civil aviation, new materials, high-energy physics, and high-temperature superconductivity benefitted most under the scheme in 1993.

The budget crunch accompanying the transition has forced the closure of many R\&D institutes since 1991, particularly in the less easily applied sciences. However, the continued deregulation of R\&D activity and essentially free pricing has led to increasing numbers of non-state R\&D institutes (although many are simply distributors and not really producers). From a standing start in 1987, the non-state component was performing $13.5 \%$ of R\&D by 1991 (see Table 2). Experts expect the dominance of contract R\&D during the transition to give way to a greater amount of in-house work once things settle down. Despite the positive signals, financing remains a crucial factor for all.

\section{Reorganization Planning Weak}

Overall R\&D financing as a share of GNP may fall to slightly below the OECD average. This will only be sufficient if personnel and infrastructure are reduced and made more efficient. At the present time the fields of science benefiting most are related to high technology, space and military technologies, where the Russian science and technology establishment believes that its R\&D community possesses competitive advantages.

The reorganization of Russian R\&D depends largely on the success of overall reform. Particularly important are an adequate legal infrastructure, the protection of property rights (both physical and intellectual), the clarification of ownership, the establishment of an effective banking system, and the reduction of artificial barriers to entry. Furthermore, an incentive system is necessary to motivate managers of enterprises to invest in R\&D.

If the policy framework seemed somewhat confusing for an outsider under central planning, when multiple levels of hierarchies and literally thousands of political, planning and financial bodies were involved, it has become no more transparent since reform began. Although some decision-making bodies have been reorganized or merged, others have either gained autonomy in financial and policy issues (e.g., the Academy of Sciences) or been dissolved. There have also been considerable changes in the command structure: the power of the central government, its agencies, committees and ministries is eroding, moving to regions and enterprises. The division of powers between the President, the government and parliamentary bodies has become progressively ambiguous; high-level personnel and their organizations (e.g., Ministries, state committees, etc.) have not developed the continuity required to establish the necessary policy-making process as their own existence is not always long enough.

Successful complementary elements of reform are essential for R\&D restructuring. Privatization and its effects such as competition and the delegation of planning an enterprise's future to the management, while
Table 2 - R\&D expenditures of non-state organizations illustrating the growth of the private research sector ( $10^{9}$ roubles). Figures for 1991 are estimates.

\begin{tabular}{|c|c|c|c|c|c|}
\hline & 1987 & 1988 & 1989 & 1990 & 1991 \\
\hline R\&D coperatives & 0.01 & 0.17 & 3.15 & 3.9 & 4.0 \\
\hline Youth Research Centres & 0.02 & 0.85 & 1.1 & 1.45 & 1.5 \\
\hline Permanent research teams of the & & & & & \\
\hline $\begin{array}{l}\text { Union of Science \& Engineering Society } \\
\text { Permanent research teams of the }\end{array}$ & & 0.12 & 0.35 & 0.5 & 0.5 \\
\hline All-Union Society of Investors & & 0.07 & 0.1 & 0.15 & 0.15 \\
\hline TOTALS: & 0.03 & 1.2 & 4.7 & 6.0 & 6.15 \\
\hline
\end{tabular}
major interest, will have a significant impact. However, since political coordination remains elusive, the establishment of a market-oriented R\&D sector lacks guidance and it has been difficult to achieve concerted efforts: the implementation, monitoring, and enforcement of new laws and regulations is frustrated Meanwhile, the lack of domestic political and institutional stability limits the involvement of foreign partners.

But the transition is particularly difficult because policy-makers are faced with a fundamental dilemma: a strong domestic scientific base is required for a progressive modern, economy, but a growing economy characterized by positive rates of return is needed to support sufficient R\&D. Nevertheless, marke economics and increased mobility are beginning to force systems to become more efficient, although simultaneously putting many scientists and engineers out of jobs. This has a positive side because these people are free to apply their talents in positions unrelated to $R \& D$, as is frequently the case in the West.

\section{Opportunities for Collaboration}

Intra- and inter-national isolation during Soviet times, part self-inflicted (internal passports, no housing market) and in part reinforced by the West (COCOM agreements of 1949 and 1950), meant that Russian scientists hardly benefited from advances elsewhere, and the global scientific community was deprived of Russian talents and findings. Soviet scientists did not travel much and had little Western literature at their disposal. New opportunities for international scientific cooperation are among the most positive benefits of the opening up of Russian R\&D. Enhanced collaboration can be expected in the economic and environmental sciences which were neglected under the Soviet regime.

However, the lack of hard currency has replaced political and bureaucratic obstacles to foreign collaboration. In addition, traditional inclinations to prevent the loss of Russian scientists and technicians persist, parti- simultaneously signalling which areas are of cularly when it comes to nuclear, biochemical and military technology. Presently, the other republics of the former Soviet Union cooperate most with their Russian colleagues (80-90\% of collaboration). The West is trying to help: the OECD countries have for the last two years increased funds for collaboration with Russia; private foundations have become more active, largely by funding projects. Cooperation often involves a Russian scientist moving to a university or research institute in the West. Many have welcomed this opportunity: indeed, several thousand R\&D personnel with advanced scientific and technical training left Russia each year since 1992. Although this may initially substantiate Russia's fear of a brain drain, the forecast that few $(10 \%)$ stay abroad permanently should ease the tension.

Next to natural resources, the scientific resources inherited from the Soviet Union probably represent the main stimulus for future growth and a successful transition to a market economy. Using new management methods, many of the R\&D resources created with Soviet central planning can be used to generate vital economic growth. However, without modifications and recognition of the need for marketability, which will entail rationalization, improvement of efficiency, and personnel layoffs, the Russian scientific establishment will not be in harmony with the market economy policy-makers are attempting to set up.

By continuing the reform efforts (that are coincidentally accompanied by a strong trend towards R\&D on a global level) Russian science can re-establish its preeminent position, improve opportunities for the community, and act as a key factor for a successful transition. Western science will then finally have a chance to collaborate in a way that has been denied for most of this century.

This article is taken from the IIASA study Research and Development Management: From the Soviet Union to Russia (Physica-Verlag, Vienna) 1993; to be published.
The forthcoming deadline for applications for magnet time allocation (February to July 1994) at the

\section{GRENOBLE HIGH MAGNETIC FIELD LABORATORY} is December 5, 1993.

Scientists of EEC countries are entitled to apply under the "Large Installation Plan" programme. Application forms are available on request.

\section{Please contact: J.C. VALLIER}

Laboratoire des Champs Magnétiques Intenses,

Max-Planck-Institut für Festkörperforschung et

Centre National de la Recherche Scientifique

B.P. 166 - 38042 Grenoble Cedex 9 - FRANCE

Tel.: +33 () 76881001

Fax: +33 () 76872197

Bitnet: vallier@ccalc.grenet.fr 